\title{
Qualidade Microbiológica de Fórmulas Lácteas Infantis em Pó Reconstituídas em Lactários Hospitalares da Região de Campinas, SP
}

Margarete Midori Okazaki (I), Harumi Colussi Horita (II), Fabiana Taminato Imazaki (I), Silvia Andréia Morelli (I), Gabriela Cristina Moita da Silva (I), Gina Maria Bueno Quirino Cardozo (I)

(I) ITAL - Instituto de Tecnologia de Alimentos (Av. Brasil, 2880 - Jardim Brasil, Campinas, SP, Brasil), (II) Metrocamp - Faculdades Metrocamp (R. Dr. Sales de Oliveira, 1661 - Vila Industrial, Campinas, SP, Brasil )

\section{Resumo}

Entre as unidades hospitalares responsáveis pela preparação de alimentos e que merecem especial atenção, devido ao risco de veiculação de microorganismos através dos alimentos, encontram-se os lactários. O presente estudo tem como objetivo avaliar a qualidade microbiológica de um total de doze amostras de fórmulas lácteas infantis preparadas em lactários hospitalares de quatro municípios paulistas (Campinas, Nova Odessa, Jundiaí e Sumaré). Cada amostra coletada foi reconstituída em frasco de mamadeira pela lactarista da unidade hospitalar, e mantida refrigerada dentro de uma caixa isotérmica durante o período de transporte ao laboratório de microbiologia do Instituto de Tecnologia de Alimentos (ITAL). Os ensaios microbiológicos foram realizados de acordo com as metodologias preconizadas pela AOAC Official Method 991.14 para a determinação de coliformes totais e Escherichia coli, ISO 6888-1 para a enumeração de Staphylococcus aureus coagulase positivos e pelo Compendium of Methods for the Microbiological Examination of Foods, da American Public Health Association, para a contagem total de bactérias aeróbias mesófilas e enterobactérias. As seis amostras avaliadas até o presente momento apresentaram bactérias aeróbias mesófilas, em níveis que variaram de ${ }^{5} \mathrm{UFC} / \mathrm{mL}$, ausência (em $1 \mathrm{~mL}$ ) de enterobactérias totais, 
Escherichia coli e coliformes totais, e ausência (em 10mL) de Staphylococcus aureus coagulase positivos. De acordo com os resultados obtidos, concluiu-se que, com relação aos coliformes totais e Escherichia coli, $100 \%$ das amostras coletadas estavam de acordo com a Resolução RDC n ${ }^{\circ}$ 12/2001 da Agência Nacional de Vigilância Sanitária (ANVISA), que estabelece 10UFC/g (ou mL) como limite máximo aceitável de coliformes totais e ausência de Escherichia coli em $1 \mathrm{~g}$ ou mL de amostra. Embora a Resolução RDC n ${ }^{\circ}$ 12/2001 não estabeleça padrões microbiológicos para as contagens de bactérias aeróbias mesófilas e enterobactérias totais em fórmulas infantis, as avaliações desses microorganismos no presente estudo foram extremamente úteis, pois observaram-se níveis de até $>10^{3} \mathrm{UFC} / \mathrm{mL}$ para aeróbios mesófilos nas amostras, indicando alguma falha nos procedimentos de preparação e/ou higienização dentro dos lactários hospitalares visitados até o momento.

Palavras-Chave: lactário, fórmulas lácteas infantis, microbiologia Agência de Fomento: 